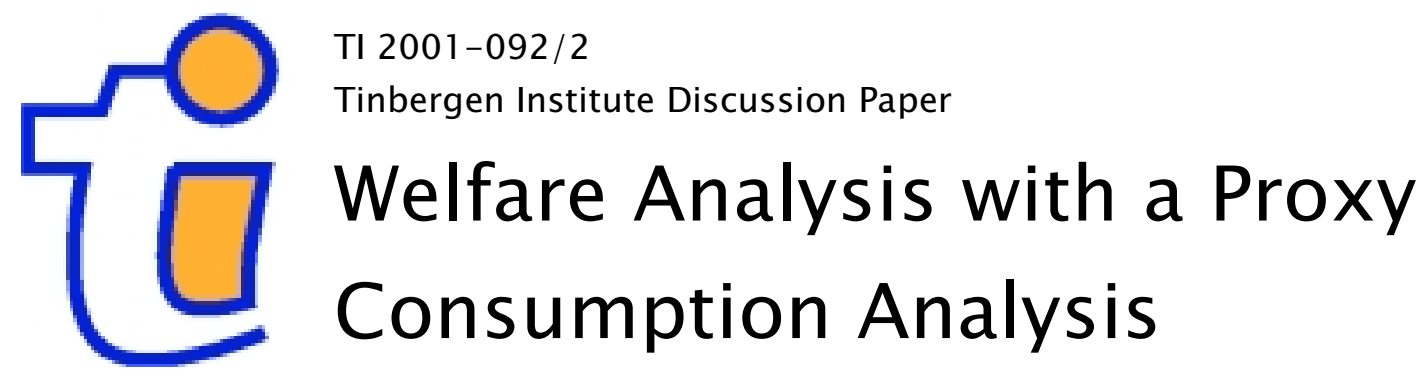

Menno Pradhan

Economic and Social Institute, Faculty of Economics and Business Administration, Vrije Universiteit Amsterdam,

Tinbergen Institute,

World Bank, and

Cornell University 
Tinbergen Institute

The Tinbergen Institute is the institute for economic research of the Erasmus Universiteit Rotterdam, Universiteit van Amsterdam and

Vrije Universiteit Amsterdam.

Tinbergen I nstitute Amsterdam

Keizersgracht 482

1017 EG Amsterdam

The Netherlands

Tel.: +31.(0)20.5513500

Fax: $\quad+31 .(0) 20.5513555$

Tinbergen Institute Rotterdam

Burg. Oudlaan 50

3062 PA Rotterdam

The Netherlands

Tel.: $\quad+31 .(0) 10.4088900$

Fax: $\quad+31 .(0) 10.4089031$

Most TI discussion papers can be downloaded at

http://www.tinbergen.nl 


\title{
Welfare Analysis with a Proxy Consumption Measure Evidence from a repeated experiment in Indonesia
}

\author{
Menno Pradhan
}

March 2001

\begin{abstract}
Every three years, Indonesia fields simultaneously two nationwide surveys which collect consumption data. One collects consumption using 23 questions, the other using 320 questions. Based on a repeated experiment in which the two questionnaires were randomly assigned across households, I examine the consequences of using a higher level of aggregation in questioning. A mapping of distribution functions reveals the combined effect of systematic differences in measurement and measurement error. Using a pseudo crosssection approach, I eliminate the effect of measurement error and find that using a high level of aggregation yields a lower consumption measure, and that the fraction of underestimation increases as consumption rises. A one percent increase in average consumption increases the fraction by which consumption is underestimated by about .4 percent point. Next, I examine the consequences of using the short consumption questionnaire in welfare analysis. Higher relative measurement error in the consumption measure derived from the short questionnaire results in higher poverty estimates even if the poverty line is adjusted to take account of the systematic underestimation. Small differences are found for analysis that is based on the rank the individual holds in the consumption distribution. In gradient analysis, it seems impossible to devise a simple correction factor for the higher consumption elasticities that follow when the short questionnaire is used.
\end{abstract}

JEL classification:

Key words: Measurement error, welfare analysis, consumption

Free University, Amsterdam and Cornell University. Address for correspondence: Economic and Social Institute, Free University, de Boelelaan 1105, 1081 HV Amsterdam, the Netherlands. Email mpradhan@econ.vu.nl. The Author would like to thank John Newman, Rob Alessie, Steve Younger, Jack Molyneaux and seminar participants at the Indonesian Bureau of Statisitics, Delta in Paris and Toulouse for useful comments. 


\title{
Welfare Analysis with a Proxy Consumption Measure Evidence from a repeated experiment in Indonesia
}

\author{
March 2001
}

\begin{abstract}
Every three years, Indonesia fields simultaneously two nationwide surveys which collect consumption data. One collects consumption using 23 questions, the other using 320 questions. Based on a repeated experiment in which the two questionnaires were randomly assigned across households, I examine the consequences of using a higher level of aggregation in questioning. A mapping of distribution functions reveals the combined effect of systematic differences in measurement and measurement error. Using a pseudo crosssection approach, I eliminate the effect of measurement error and find that using a high level of aggregation yields a lower consumption measure, and that the fraction of underestimation increases as consumption rises. A one percent increase in average consumption increases the fraction by which consumption is underestimated by about 4 percent point. Next, I examine the consequences of using the short consumption questionnaire in welfare analysis. Higher relative measurement error in the consumption measure derived from the short questionnaire results in higher poverty estimates even if the poverty line is adjusted to take account of the systematic underestimation. Small differences are found for analysis that is based on the rank the individual holds in the consumption distribution. In gradient analysis, it seems impossible to devise a simple correction factor for the higher consumption elasticities that follow when the short questionnaire is used.
\end{abstract}

JEL classification:

Key words: Measurement error, welfare analysis, consumption

The Author would like to thank John Newman, Rob Alessie, Steve Younger, Jack Molyneaux and seminar participants at the Indonesian Bureau of Statisitics, Delta in Paris and Toulouse for useful comments. 


\section{Introduction}

Including a consumption module in a household survey increases its potential usefulness for policy analysis but also increases the cost substantially. In developing countries, consumption is generally considered the preferred single indicator of welfare among economists. Consumption data, however, take a lot of time and effort to collect. In some instances, households are asked to maintain a diary of their expenditures, which are then collected on a second visit. Other surveys use recall questions and ask respondents many detailed questions on their expenditure patterns and consumption of home production. For example, the 1996 Nepal Living Standard Measurement Survey used 9 questions for each of the 67 food items, 1 or 2 questions for the 58 non-food items and 5 questions for each of the 16 durables for which the survey collected consumption data. Special attention needs to be devoted to imputing a value for the consumption of housing, durables and home produced goods ${ }^{1}$. The high costs have spurred research into how well other welfare measures can proxy welfare as measured by consumption ${ }^{2}$.

A low cost alternative to relying on non-consumption welfare measures is to collect consumption using fewer questions. This can be achieved using a higher level of aggregation in the consumption categories. The consequences of using a shorter consumption questionnaire is the topic of this paper. The country of focus is Indonesia. Indonesia's socio

\footnotetext{
${ }^{1}$ See Deaton and Zaidi (1999) for a discussion on the issues that arise when constructing a consumption measure.

2 Montgomery, Mark R., et al. (2000) find, using data from five developing countries, that proxy indicators used in demographic research are poor predictors of household consumption but may be used to test hypothesis. For Ghana, Cote d'Ivoire and Vietnam, Sahn and Stifel (2000) find a rank correlation ranging from .43 to .57 when household are ordered according to per capita household consumption and a composite asset indicator. Shubham Chaudhuri, Martin Ravallion (1994) look at how well chronic poverty can be predicted
} 
economic survey follows a Core/Module design (Surbakti, 1997). Every year a Core questionnaire is administered which collects various socio-economic indicators along with household consumption using a short questionnaire. Once every three years one third of the sampled households receives a detailed consumption questionnaire (Module) in addition to the Core. Since the samples are drawn from the same population and the surveys are administered at the same time, this setup provides a unique large scale repeated experiment to investigate the effects of collecting consumption using a limited set of questions. At present there are comparable data for 1993, 1996 and 1999.

Other experiments have found that reducing the number of question yields a lower consumption measure. In El Salvador, reducing the number of food questions from 72 to 18 and the number of non-food questions from 25 to 6 yielded ratios of 1.27 for average food and 1.40 for overall consumption (Joliffe and Scott, 1995). In Jamaica a similar experiment yielded ratios of 1.26 for both food and non-food (Statistical Institute and Planning Institute of Jamaica, 1996). The Indonesian experiment is different from the ones quoted above in that the reduction of the number of questions is much greater. The long consumption questionnaire collects food consumption using 218 categories while the short uses only 15 . For non-food the reduction is from 102 to 8. In addition, the Indonesian experiments is on a larger scale and repeated over time. This allows us to investigate whether the underestimation of a shorter questionnaire is sensitive to changes in prices and incomes. There is also evidence that using more detailed questions yields a higher income measure in developed countries (Tummers 1994).

using static welfare indicators. Elbers, Lanjouw and Lanjouw (2000) investigate how well data collected in a census can predict village welfare. 
The objective of the paper is to investigate the sensitivity of welfare analysis to the level of aggregation that is used when collecting the welfare measure (consumption). This is of importance for instance for cross-country comparisons. Cross-country poverty comparisons, as for example reported in the World Development Report 2000 (World bank, 2000), put great effort ensuring that the poverty line represents the same purchasing power across countries. Little attention is paid to the way in which the underlying welfare measure was collected. If, as we will conclude in this paper, the aggregate consumption measure is sensitive to the way in which consumption was collected, some of the cross-country comparison may have to be reevaluated. The Indonesian experiment allows us to investigate how much welfare measures are affected and whether it is possible to design correction factors based on a period in which two surveys are available. We will look at poverty comparisons, inequality and income inequality of non-consumption welfare measures.

The paper can also serve as a guide for those contemplating to field a consumption questionnaire and wondering what would be the effect of reducing the number of questions. The findings in this paper may help in deciding for which consumption categories the number of questions can be reduced and for which detailed questions are needed in order to maintain a reasonable level of accuracy. The factors at play can be different depending on the consumption category. For some items, which are socially desirable, a respondent could be tempted to report a higher expenditure if not prompted for details. The opposite could occur for items which do not carry a high esteem value, such as alcohol. And of course there is the risk of forgetting certain consumption items if the aggregated category comprises many consumption items. The risk of this happening becomes larger as the household gets richer and the consumption pattern becomes more varied. 
The organization of the paper is as follows. Section 2 discusses the design of the survey and experiment in more detail. Section 3 compares the consumption measures from the long and short questionnaire for the 1993, 1996 and 1999 Susenas. Section 4 discusses the consequences of using the consumption measure from the short questionnaire in welfare analysis. Section 5 summarizes.

\section{The Susenas household survey}

The Susenas is Indonesia's national socio economic survey. Every year, around 200,000 households are sampled. A subset of around 65,000 households received a Module in addition to the Core questionnaire, the latter being administered to all households. The Module rotates between one focusing on (1) income and consumption, (2) welfare, socioculture, criminality and tourism, and (3) health nutrition education and home environment. This analysis is based on the three years where the income and consumption module was administered. The Module questionnaire collects for every food item separate the expenditures and value of home production. The reference period for food is one-week. For non-food the Module survey collects the value of consumption separate for a one-month and a one-year reference period. The Core questionnaire only collects the value of consumption using one question for each broad category. The reference periods are the same as in the Module. The data tapes do not distinguish between missing observations and zero consumption. The Module consumption questionnaire is nested in the Core consumption questionnaire. In fact, the last page of the Module questionnaire contains a summary page identical to the Core questionnaire where the interviewers are asked to aggregate consumption within each subgroup. For households that received the Module, consumption is not again separately collected using the short Core questionnaire. The aggregates of the Module are copied into the Core. The analysis will thus be based on the a comparison of the Module 
consumption measure for those households which received this questionnaire and the Core consumption measure for the households which were not included in the Module sample.

While the Module consumption figures are used for official poverty statistics, it is generally recognized that the aggregate private consumption derived from the Module is an underestimate. A comparison with private consumption as reported in the National accounts data (IMF 2000, source Indonesian Central Bank) yields an underestimation ratio of 2.0 in 1993 and 1996 and 2.2 in 1999. According to the Central Bureau of Statistics, the main cause is a high rate of non-response among rich households ${ }^{3}$.

The survey follows a stratified clustered random sample design. The sample sizes are chosen such that the Core is representative at the district (kabupaten) level, by urban/rural, and the Module at the provincial level, again by urban/rural. Consequently, the level of stratification varies for the Core and the Module. The Susenas data tapes come with two sets of weights, one for all households - to analyze Core data - and one for Module households only. Since the objective is to compare the Module households with the "Core only" households (those that did not receive the Module, in the remainder referred to as simply the Core) the supplied weights cannot be used directly. The weights for the "Core only" households have been constructed using $w_{k i}^{*}=w_{k i} \frac{\sum_{j=1}^{N_{k}^{M}+N_{k}^{C}} w_{k j}}{\sum_{j=1}^{N_{k}^{C}} w_{k j}}$ where $i$ identifies a household which received the Core only; $w$ are the weights supplied for the Core households; $k$ denotes

\footnotetext{
${ }^{3}$ Based on discussion with seminar participants at the Indonesian Bureau of Statistics.
} 
an urban or rural district; $N_{k}^{M}$ is the number of households which received the Module in district $k$; and $N_{k}^{C}$ the number of households which received the Core only.

The Core/Module design of the Susenas was introduced in 1992. Before the introduction of the new Core questionnaire, it was field tested in three provinces. A specific focus of the fields test was how well the short consumption module was able to collect aggregate consumption in comparison to the long questionnaire, which had been used previously. The results of the field test are discussed in World Bank (1992, annex 4.2). Since not all readers will have access to this source, I will summarize the findings here. The questionnaire was field tested in three provinces including 8000 households. In West Nusa Tengara and South Kalimantan, households were randomly assigned a short or a long questionnaire, a design similar to that used in the subsequent analysis. The data could not reject the hypothesis that the distribution function of food consumption collected by the two questionnaires was different. Average food consumption differed less than one percent. Average non-food consumption, based on a one-month reference period, was underestimated by somewhat less than 15 percent if the Core questionnaire was used. Most of the difference was caused by the housing and "good and services" categories. In West Sumatra, where all households received both the Core and the Module, a simple linear regression yielded an $\mathrm{R}$ squared of 85 percent. Interviewing time for a complete Core - including the socio-economic questions - was 52 minutes while the Module consumption questionnaire took on average 82 minutes to administer. The encouraging findings of the field test did not result in any changes in questionnaire design.

Of course, there are many reasons one could think of why the results of the field test may not hold once implemented. First, the field test was fielded as such. Interviewers knew 
they were testing a new consumption questionnaire and therefore may have collected data more carefully than they would have done otherwise. Second, economic conditions have changed since the field test of the survey. Indonesia experienced growth rates of around 8 (percent) from 1992 to 1997 and plunged into crisis in 1997 yielding GNP per capita growth rates of -16.2 percent from 97/98 and 0.3 percent in 1998/1999 (World Bank 2000,1999).

\section{Comparison of two consumption measures}

Comparisons are based on real consumption, measured in urban prices prevailing in 1996. In 1997, Indonesia was hit by a severe economic crisis which resulted in sharp increases in food prices. From 1996 to 1999, the food component of the CPI increased by 144 percent whereas the non-food component of the CPI increased by 75 percent. Separate deflators are used for food and non-food. Regional and intertemporal deflation is based on the CPIs as reported by the Central Bureau of Statistics (BPS 1996, 1999). Indonesia's CPIs are based on prices collected in provincial capital cities. Based on analysis of unit values collected in the Susenas Module, Asra (1999) suggests that food (non-food) prices in urban areas are about 16 (12) percent higher than in rural areas. I use his factors to deflate rural consumption to urban prices.

Table 1 shows various summary statistics to describe the distribution of per capita consumption using the short and long questionnaire for the three years. The differences in the means turn out higher than what was found during the field test. The degree by which average consumption is underestimated varies by year, ranging from -11.7 to -19.6 percent. The degree of underestimation is the highest in 1996, when also average consumption was at its peak. For food the degree of underestimation of the mean is less, ranging from -3.5 percent in 
1993 to -11.4 percent in 1996 . The difference in non-food consumption is the largest. The underestimation of the mean ranges from -23.8 percent in 1993 to -30.1 percent in 1996 . The standard deviations for the log per capita consumption are slightly higher for the Core. Note that when the Core underestimates the Module by a fixed fraction the standard deviations would have been the same. The higher dispersion stems from the nonfood consumption, for $\log$ food consumption the standard deviations are often smaller for the Core. The difference between the Core and the Module quartiles increases as the quartile reflects a wealthier group. This is mostly due to the increasing non-food share in consumption. Within food and nonfood consumption, the differences between the quartiles is much less pronounced. Inequality, as measured by the Gini coefficient, is slightly higher for the Core food consumption and Module non-food consumption. Combined, the Module yields a higher inequality measure total consumption. Although inequality varies considerably over time, the absolute difference between the Core and the Module Gini coefficient is quite similar. Figure 1 presents kernel density estimates of log per capita food and non-food consumption in 1996, the year that the differences are the largest. The shape of the Core and Module density functions is very similar. In all cases, the Core density function is slightly more peaked. The dispersion of nonfood consumption is much larger than that of food.

Because we do not have data for the short (from the Core) and the long (from the Module) consumption measure for the same households, we cannot estimate the function that maps one into the other directly. A seemingly plausible alternative is to plot the percentiles of the two consumption measures against each other. If the two questionnaires yield the same consumption measure, the CDFs should overlap. This is done in Figure 2. The graph is constructed as follows. Let $s$ denote the log per capita monthly consumption measure generated by the short questionnaire and $l$ denote the equivalent for the long consumption 
questionnaire. The function shown in Figure 2 is $s(l) / l=\exp \left(F^{-1}(G(l))-l\right)$ where $F$ and $G$ are the cumulative distribution functions for $s$ and $l$ respectively.

To help interpret the graphs it is instructive to set up a model. Suppose consumption is distributed log normal and that the long consumption questionnaire measures it with a multiplicative random lognormally distributed measurement error.

$$
c \sim n\left(\mu, \sigma_{c}^{2}\right) \quad l=c+v \quad v \sim n\left(0, \sigma_{v}^{2}\right)
$$

where $c$ is the log of consumption. The short consumption questionnaire measures consumption with systematic bias and random measurement error. Assuming a linear relation for the systematic bias this yields

$$
s=\alpha+\beta c+\varepsilon \quad, \varepsilon \sim n\left(0, \sigma_{\varepsilon}^{2}\right)
$$

where $\varepsilon$ is the random measurement error. Under the above assumptions the CDFs of $l$ and $s$ can be written as

$$
G(x)=N\left(\frac{x-\mu}{\sqrt{\sigma_{c}^{2}+\sigma_{v}^{2}}}\right), F(x)=N\left(\frac{x-\alpha+\beta \mu}{\sqrt{\beta^{2} \sigma_{c}^{2}+\sigma_{\varepsilon}^{2}}}\right)
$$

where $N$ is the cumulative standard normal distribution function. A mapping of the distribution functions in this case yields $s$ as a function of $l$

$$
s(l)=\alpha+\beta \mu+(l-\mu)\left(\frac{\sqrt{\beta^{2} \sigma_{c}^{2}+\sigma_{\varepsilon}^{2}}}{\sqrt{\sigma_{c}^{2}+\sigma_{v}^{2}}}\right)
$$

It directly follows that when there is no measurement error $\left(\sigma_{v}^{2}=\sigma_{\varepsilon}^{2}=0\right)$ the mapping of the distribution functions yields back the systematic relationship between the two consumption measures. With measurement error that is not true anymore. Rearranging terms yields 
$s(l)=\alpha+\beta l+\beta\left(\frac{\sqrt{\sigma_{c}^{2}+\sigma_{\varepsilon}^{2} / \beta^{2}}}{\sqrt{\sigma_{c}^{2}+\sigma_{v}^{2}}}-1\right)(l-\mu)$

,indicating that if $\frac{\sigma_{\varepsilon}^{2}}{\beta^{2}}>\sigma_{v}^{2}$, the function will underestimate the systematic relationship for values of $l$ below the mean and overestimate for values above the mean. The above condition holds if the relative measurement error using the short consumption questionnaire is larger than when using the long consumption questionnaire. Under the same condition the function's first derivative with respect to $\mu$ is negative. As mean consumption increases, the last term in (5) will become smaller.

Let's now turn back to Figure 1 . Throughout $s(l) / l$ is smaller than one, indicating that the short consumption questionnaire systematically underestimates consumption. The downward sloping section of the curves around the average consumption indicates that as consumption rises, the fraction by which the short consumption underestimates consumption increases. In the model above this would imply that $\beta<1$. The upwards sloping section for low consumption levels and the fading of the downwards sloping trend at high consumption level also indicates that measurement error is present and that indeed the relative measurement error for the short consumption is greater than for the long consumption. Measurement error causes an underestimation at low consumption levels and an overestimation at consumption levels above the mean. The fact that the curves shift over time corresponds with the trends in mean consumption. In 1996 average consumption was at its peak resulting in the lowest estimated $s(l) / l$ function. As demonstrated, this does not necessarily imply that the systematic relationship between the short and long consumption measure has changed over time. 
The presence of measurement error makes it impossible to recover the structural relationship between the short and long consumption questionnaire by mapping percentiles. More structure is needed to make progress. Assuming a relationship as postulated in (1), we can estimate the regression by taking averages over cohorts. Substituting (1) into (2) and adding an error to take account of model misspecification yields

$$
s_{i j}-\varepsilon_{i j}=\alpha+\beta\left(l_{i j}-v_{i j}\right)+\omega_{i j}
$$

where $j$ denotes the cohort the household belongs to and $i$ denotes the household. $\omega_{i j}$ is a model error term with a conditional mean zero. Taking averages within cohorts yields

$$
\overline{\left(s_{j}-\varepsilon_{j}\right)}=\alpha+\beta\left(\overline{\left.l_{j}-v_{j}\right)}+\bar{\omega}_{j}\right.
$$

Because $\bar{\varepsilon}_{j}$ and $\bar{v}_{j}$ are uncorrelated and tend to zero as the number of observations in the cohort increases (7) can be estimated by taking averages within each cohort which then serve as data in the regression. In this analysis, I have used the 298 districts as cohorts. This approach can be viewed as an application of two sample two stage least squares (Angrist and Krueger 1992) where the cohort dummies are used as instruments. The identifying assumption is that the region in which the household lives does not influence short consumption, conditional on the level of long consumption. In other words, there is no direct effect of the region in which one lives on the ability to estimate one's consumption. To allow for a more flexible functional form I have estimated (8) using locally weighted regression (lowess). Figure 3 presents the results. On the vertical axis, I have plotted the predicted Core consumption measure as a ratio of the Module consumption measure, making the figure directly comparable with Figure 2. Similar curves for food and non-food are presented in Figure 4. 
The curves show a similar pattern of systematic underestimation over time. From 1993 to 1999 the systematic underestimation of the Core gradually increased. The vertical lines in Figure 3 denote the per capita consumption decile cutoff points in 1996. For those in the poorest two deciles, the Core overestimated Module consumption in 1993. This effect vanished for the second decile in 1996 and disappeared in 1999. As consumption increases, the fraction by which the Core underestimates increases also. The curve flattens for the upper two deciles, suggesting a maximum underestimation of the Core of around 23 percent.

The intertemporal elasticity of the underestimation of the Core is higher than follows from a purely cross sectional analysis. The line with the three crosses in Figure 3 is constructed by comparing the mean of log consumption arising from the short and long questionnaire in the three years. The vertical axis shows by which fraction per capita consumption is underestimated. Note that this comparison, based on distribution functions, is valid within the context of the presented model because the last term in (4) vanishes when $l=\mu$. A one percent increase in average consumption leads to an increase in the underestimation of the Core of around .45 percent point. Around the mean, the cross sectional estimates predict an increase in the underestimation of around .2 percent point.

Figure 4 presents the shows the estimates separately for food and non-food consumption. The elasticity of the underestimation with respect to Module consumption is higher for food than for non-food. For food, the systematic underestimation increased from 1993 to 1996. From 1996 to 1999, the underestimation increases further for the poor, but decreases for the rich. This possibly is related to the high food price increases during the economic crisis. For non-food the pattern is more stable. The maximum underestimation is around 35 percent. 
Because the Core and Module questionnaire are nested - every question in the short consumption questionnaire corresponds to a set of questions in the long consumption questionnaire - we can make the comparison of averages at a more disaggregated level. Table 2 presents such an analysis for 1996, the year in which the difference was the largest. The table also shows the effect of using different recall periods for non-food. Official statistics in Indonesia are based on weekly food consumption and yearly non-food consumption. The questionnaire however also collects non-food consumption also with a one-month recall period. Increasing the recall period from one-month to one-year increases the fraction of underestimation for non-food from -27.8 to -30.1 percent. In food, we find high underestimations for vegetables, fruits and prepared foods. The difference in prepared food contributed 15.6 percent to the total difference in consumption. For some food items (tuber, pulses, spices, alcoholic beverages and tobacco) the average Core consumption turns out higher than that of the Module. Most of the difference in total consumption, 68 percent, stems from differences in non-food consumption. Housing clearly is the most problematic non-food consumption item. The Core underestimates housing by 27 percent contributing about 26 percent to the total difference in consumption. Large differences are also found for "Miscellaneous goods and services" and durable goods. Although the underestimation for these items is larger than for housing - around 50 percent - the contribution to the difference in total consumption is only around 15 percent. The Core overestimates average education expenditures by around 17 percent.

Housing is clearly the most problematic consumption item of all non-food expenditures. Because of this, I discuss the differences in questionnaire design in more detail and investigate remedies to solve the discrepancies. The Module housing section asks the respondents to impute a housing rent if the house is owned or provided free of charge. In 
addition, the Module consumption questionnaire contains separate questions for maintenance costs, electricity, water, firewood and several other kinds of fossil fuels or gasses. The Core, on the other hand, has only one question with no explicit instruction to impute rent for house owners. One possible remedy to resolve the difference between the Core and Module housing consumption is to rely on estimates of a hedonic price regression of housing. The Core contains 11 questions on the quality of the house and sanitary facilities. Since the Core is administered to all households, we have these data available for both the Core and Module households. A hedonic price regression based on the Module households, with log housing expenditures as the dependent variable and the housing quality variables along with a set of regional dummies as independent variables yields and $\mathrm{R}$ squared of .64. The estimated coefficients are in Table 4.

As expected, there is no significant difference between the Core and Module households when using predicted housing consumption ${ }^{4}$ (see Table 3 , as a result of the random assignment of questionnaires). The mean predicted consumption however is substantially smaller than the mean actual consumption from the Module households. To the extent that this is caused by measurement error (resulting from the difficulty the respondent has in estimating an imputed rent), it may be desirable to use the predicted housing consumption instead of the actually reported. Using predicted housing consumption reduces the difference in total consumption between the Core and Module to 14 to 15 percent, depending on the reference period used for non-food consumption.

In the remainder of the paper, I will use a consumption measure were housing is not imputed. Although I believe the consumption measure with imputed housing consumption is

\footnotetext{
${ }^{4}$ I use the smearing estimate as proposed by Duan (1983) which is defined as $\exp \left(x_{i} \hat{\beta}\right) * N^{-1} \sum \exp \left(\hat{\varepsilon}_{i}\right)$
} 
preferable, an important objective of the paper is to investigate the usefulness of the Core consumption measure given that the official statistics are based only on the actual Module consumption.

\section{Welfare analysis}

Now we turn to the question of what one can do in terms of welfare analysis when one only has the short consumption questionnaire available. This is a question of practical importance in Indonesia. In two out of every three years, the Susenas only collects consumption data using the short consumption questionnaire. The question is also of general importance for researchers basing their analysis on consumption data generated from short questionnaires who wish to have a handle on the magnitude of the errors they are making.

We will discuss the consequences of using the short consumption questionnaire for three types of analysis commonly found in the poverty literature. The first is poverty measurement. How well can we measure poverty by constructing an adjusted poverty line for the Core? The second type is "rank" analysis. In this type of analysis, the population is ranked according to a welfare measure, usually per capita consumption. Next, income inequality of a non-consumption welfare measure, such as enrollment or malnutrition, is investigated.

Concentration curves or quintile tables are common examples. The crucial distinction here is that the analysis is based only on the rank that an individual holds in the per capita consumption distribution. The third type is "gradient" analysis. Here we are interested in the elasticity of a non-consumption welfare measure with respect to per capita consumption. This type of analysis typically involves estimating a regression with the non-consumption welfare 
measure as the dependent variable and log per capita consumption as one of the explanatory variables.

Measurement error complicates the analysis of poverty. Measurement error increases the poverty estimate as long as the poverty line is below the mode of the consumption distribution. Measurement error increases the probability weight of tails of the distribution, which is the basis of the poverty estimate. For the head count ratio, the effects are easily demonstrated using the model as postulated in (1) and (2). Let $z$ denote the log poverty line. The head count ratio based on the long consumption measure is $G(z)$ which overestimates poverty if there is measurement error $\left(\sigma_{v}>0\right)$ and $z<\mu$. Using $z_{s}=\alpha+\beta z$ as a poverty line for the short consumption measure ${ }^{5}$ yields as a head count ratio $F\left(z_{s}\right)$ which also overestimates poverty if $\sigma_{\varepsilon}>0$ and $z_{s}<\alpha+\beta \mu$. The latter estimate will yield a higher poverty estimate than the one based on the long consumption measure if the relative measurement error of the short consumption measure exceeds that of the long one $\left(\sigma_{\varepsilon}^{2} / \beta^{2}>\sigma_{v}^{2}\right)$

One seemingly plausible way around this problem is to adjust the poverty line for the Core such that it yields the same head count for a given year: $z_{s}=F^{-1}(G(z))$. This can be done for a year that both the Module and Core are available. For the other years the head count ratio can be analyzed using the short consumption measure in conjunction with the newly established "short poverty line". Such an approach however is not valid. Working

\footnotetext{
${ }^{5}$ Lanjouw and Lanjouw (1999) study the effect of using a partial consumption measure (food consumption) for poverty measurement. Their approach is similar in that they use the estimated Engel curve whereas I 1 use the estimated structural relation between the short and the long consumption measure estimated in the previous section.
} 
through the same derivation as above, it immediately follows from (5) that the short poverty line depends on $\mu$, the average consumption. An updating rule that would ensure the same head count ratio under the assumption of constant variances of the log consumption and measurement error is

$$
z_{t+1, s}=z_{t, s}-\left(\frac{\sqrt{\sigma_{c}^{2}+\sigma_{\varepsilon}^{2} / \beta^{2}}}{\sqrt{\sigma_{c}^{2}+\sigma_{v}^{2}}}-1\right)\left(\mu_{t+1, s}-\mu_{t, s}\right)
$$

where $z_{t, s}$ is the anchored short poverty line for a year that both the Core and the Module are available and $\mu_{s}=\alpha+\beta \mu$, the mean of the log Core consumption measure.

Table 5 presents head count ratios ${ }^{6}$. The poverty line is set at 38,246 Rupiah per capita in urban 1996 prices and applied to the Module data. Two sets of poverty lines are applied to the Core. The first is constructed by applying for each year separately the structural relationship as depicted in Figure 3. For the second set of poverty lines is constructed such that it yields the same head count ratio as the Module data. As expected the Core poverty estimates based on the first set exceed those of the Module. The relative measurement error of the Core is higher than that of the Module. The differences are substantial; the head count ratio is around 4 percent point higher if the Core data are used. The second set gives us an idea of how the poverty line needs to be updated as average consumption rises. In (6), we can take first differences of the log poverty lines and the mean log Module consumption figures (from Table 1). This yields an estimate of 0.947 (1993-1996) and 0.976 (1996-1999) for the

\footnotetext{
${ }^{6}$ The estimates differ from those reported earlier in for instance Pradhan, Suryahadi, Sumarto and Pritchett (2000) or Biro Pusat Statistik (1996). The reason for this is that I use in this study price deflators which reflect general consumption patterns whereas most poverty studies use the regional poverty lines as price deflators. In the latter the food share is higher. Readers interested in absolute levels of poverty should refer to the studies quoted above.
} 
large expression in brackets in (8). The expression can be used as an estimate of minus the elasticity of the Core poverty line with respect to mean log Core consumption if one's objective is to obtain the same head count ratio as when the Module were used. It does not imply equality of the higher order FGT poverty measures. Even though the estimate is rather constant over time, it is larger that we expected. In terms of the model, it would imply an extremely large relative measurement error in the Core. There is clearly room for improvement. The linear model for the systematic part of the model (which does not show from Figure 3) and normality pose overly strong restrictions on the model. If the objective is to predict Module poverty based on Core data, these will need to be relaxed. This is however beyond the scope of this paper. All I demonstrated is that both measurement error and systematic underestimation have to be accounted for when embarking on such an endeavor.

In the rank analysis, my prior is that the concentration curves based on the short consumption to show less income inequality than the one based on the Module consumption. If the structural underestimation is a monotonically increasing function of Module consumption (as found in Figure 3), it will not change the ranking. The measurement error causes a reclassification, resulting in a weaker relation between consumption and benefits. Since the underestimation is higher for the rich, the effect of the measurement error will be less for the higher income groups.

Since the Core collects a range of non-consumption welfare measures for both the Core and Module households identically, I can test my expectations empirically. As nonwelfare measures I use school enrolment for children in the junior and senior secondary age group, whether the respondent sought medical care in the past month and whether young children received a complete set of vaccinations. Figure 5 and Figure 6 present the 
concentration curves generated separately using the Core and Module consumption measure. In general, the concentration curves lie remarkably close. For all but the curve for vaccinations, we find that the expected relation that the using the short consumption shows less income inequality for the lower income groups. Only for the vaccination we find that the Core yield a slight pro-poor bias while the Module indicates no income dependence.

In the gradient analysis, my prior is that the estimated elasticities based on the Core are higher than those based on the Module. Suppose we wish to obtain the consumption elasticity of some non-consumption welfare measure $y$. In that case the elasticity can be estimated by

$$
y=\delta+\gamma l+\eta
$$

where the variable of interest is $\gamma$. Because of omitted variables on the RHS of the equation, consumption needs to be instrumented. Let $Z$ be a vector of instruments for consumption

$$
c=Z \varphi+\omega
$$

Equations (1), (9) and (10) can be estimated by two stage least squares. The resulting estimate of $\gamma$ is an unbiased estimate of the elasticity of consumption. Instrumenting eliminates the bias caused by measurement error in $l$. When $l$ is replaced by $s$ in equation (9), and $s$ is a function of $c$ as postulated in (2), instrumenting $s$ with $Z$ will yield an estimate of the elasticity divided by $\beta$. Because the short consumption measure rises more slowly than the long as true consumption rises, the estimate of $\gamma$ will be an overestimate. By estimating both models separately for the Core and the Module we can investigate the magnitude of this bias.

For the gradient problem, I present estimates of $\gamma$ in (9) using the housing variables collected in the Core as instruments (see Table 4 for a full list). For the Core column I 
replaced $l$ by $s$ and used the same instruments. The results are in Table 6 . As expected, the estimate of $\gamma$ is higher if the short consumption measure is used. The ratio of the two estimates of $\gamma$ varies from .60 to .92 . One possible explanation for the large differences is that the equations have been estimated for different subsamples (enrolment only for children, contact rate for all) and that the linear approximation assumed in (2) varies by group. Based on the large differences it does not seem realistic to suggest correction for gradient estimates based on the Core.

\section{Conclusions}

This paper exploited a repeated large-scale experiment in Indonesia allowing an examination of the effect of using fewer questions to collect consumption data. The analysis indicates that using fewer questions yields a lower consumption measure. The fraction by which consumption is underestimated increases as consumption rises. Whether or not a short consumption questionnaire suffices, thus depends on the level of economic development, which is directly related to the variety of consumption patterns and the share of non-food in total consumption. For the case of Indonesia, reducing the number of questions from around 320 to 23 yields to a underestimation of consumption ranging from 12 to 20 percent over the period from 1993 to 1999. Imputing rent values using a hedonic price approach decreases the underestimation by 6 percent point in 1996 .

Away from the mean, a comparison based on mapping percentiles is not valid in the presence of measurement error. I estimated the structural underestimation of the Core consumption measure by applying two sample two stage least squares using regional cohorts as instruments. The curvature of the relationship is similar over time although the degree of 
underestimation still rises with average consumption. In 1999, the cross sectional elasticity flattened for food consumption probably as a result of the high increases in food prices and the less varied diet that followed.

The effects of using a shorter consumption measure for welfare analysis vary. Even after purging the systematic underestimation of short consumption measure, measurement error still causes higher poverty estimates if the short consumption measure is used. I suggested a method to update the poverty lines for the Core if one's objective is to equalize the head count ratios. Concentration curves, which are based on the rank in the individual holds in the consumption distribution, are very similar for both consumption measures. The point estimates in a gradient analysis are higher when the Core is used and the ratio by which the Core overestimates the consumption elasticity varies substantially depending on which welfare measure is used. It thus seems unadvisable to rely on the short consumption measure for gradient analysis.

The design of the Susenas survey seems to strike a good balance between cost effectiveness and precision, which may be applied elsewhere. As the effect of using less questions increases as consumption rises, the model seems more suitable for low income countries. Collecting consumption using few questions allows for welfare analysis, especially where the main interest is in ordering households from poor to rich. Correction factors can be developed using those years in which the long questionnaire is administered along with the short questionnaire. Regular anchoring of these factors appears necessary as the structural relationships vary over time. 


\section{References:}

Angrist, Joshua and Alan Krueger (1992) "The Effect of Age at School Entry on Education Attainment: An Application of Instrumental Variables with Moments from Two Samples", Journal of the American Statistical Association, vol 87, no418, pp328-336. Asra, Abuzar (1999) "Urban-Rural Differences in Costs of Living and Their Impact on Poverty Measures”, Bulletin of Indonesian Economic Studies; v35 n3 December 1999, pp. 51-69.

Biro Pusat Statistik (1996, 1999) “Statistical Yearbook", Central Bureau of Statistics, Jakarta, Indonesia.

Deaton, Angus and Salman Zaidi (1999) "Guidelines for Constructing Consumption Aggregates for Welfare Analysis", working paper, Princeton University.

Duan, Naihua (1983) “Smearing Estimate: A Nonparametric Retransformation Method", Journal of the American Statistical Association, vol 78, nr 383, pp 605-610.

Elbers, Chris, Jean O. Lanjouw and Peter Lanjouw (2000) "Welfare in villages and Towns" Tinbergen Institute Discussion paper no 029/2, Amsterdam.

International Monetary Fund (2000) "International Financial Statistics", Washington DC Joliffe, Dean and Kinnon Scott (1995) "The sensitivity of measures of household consumption to survey design: results from an experiment in El Salvador, Policy research Department, World Bank, Washington DC.

Lanjouw, Jean Olsen and Peter Lanjouw (1999) "Can we Compare Apples and Oranges? Poverty Measurement based on Different Definitions of Consumption”, working paper, Yale University.

Montgomery, Mark R., et al. (2000) "Measuring Living Standards with Proxy Variables", Demography v37, n2 (May 2000): 155-74. 
Pradhan, Menno, Asep Suryahadi, Sudarno Sumarto and Lant Pritchett (2000)

"Measurements of Poverty in Indonesia: 1996, 1999, and Beyond", SMERU working paper, Jakarta, Indonesia.

Sahn, David and David Stifel (2000) "Exploring Alternative Measures of Welfare in the Absence of Expenditure Data", draft mimeo, Cornell University.

Shubham Chaudhuri, Martin Ravallion (1994), How well do static indicators identify the chronically poor?, Journal Of Public Economics (53)3 (1994) pp. 367-394

Statistical Institute and Planning Institute of Jamaica (1996) Jamaica survey of living conditions, 1994 Kingston, Jamaica.

Surbakti, Pajung (1997) "Indonesia's National Socio-Economic Survey: a continual data source for analysis on welfare development", Central Bureau of Statistics, Jakarta, Indonesia.

Tummers (1994) "The effect of Systematic Misperception of Income on the Subjective Poverty Line", in The Measurement of Household welfare, eds Blundell, Preston and Walker, Cambridge University Press.

World Bank (1992) “Indonesia: Public Expenditures, prices and the poor”, Indonesia Resident mission 11293-IND, Jakarta.

World Bank (1999,2000) “World Development Report”, World Bank, Washington DC. 
$\underline{\text { Tables }}$

Table 1 Descriptive statistics for Module and Core consumption measures in 1993,1996, 1999 (in 1996 urban national prices using separate deflators for food and non-food, based on one week recall for food and one year recall for non-food)

\begin{tabular}{|c|c|c|c|c|c|c|c|c|c|}
\hline \multirow{2}{*}{$\begin{array}{l}\text { Per capita monthly } \\
\text { consumption }\end{array}$} & \multicolumn{3}{|c|}{ Module } & \multicolumn{3}{|c|}{ Core } & \multicolumn{3}{|c|}{ Percent difference /a } \\
\hline & 1993 & 1996 & 1999 & 1993 & 1996 & 1999 & 1993 & 1996 & 1999 \\
\hline \multicolumn{10}{|l|}{ Consumption } \\
\hline Avg. consumption & 58,916 & 72,088 & 64,771 & 52,048 & 57,926 & 54,419 & -11.7 & -19.6 & -16.0 \\
\hline std deviation & 49,258 & 68,967 & 55,622 & 41,763 & 50,598 & 42,001 & & & \\
\hline Avg. $\log$ cons & 10.81 & 10.99 & 10.91 & 10.70 & 10.79 & 10.76 & -10.0 & -17.9 & -14.4 \\
\hline std deviation & 0.55 & 0.57 & 0.53 & 0.52 & 0.55 & 0.51 & & & \\
\hline first quartile & 33,668 & 39,655 & 38,145 & 31,166 & 33,500 & 33,365 & -7.4 & -15.5 & -12.5 \\
\hline median & 46,052 & 54,653 & 51,297 & 41,792 & 45,503 & 44,705 & -9.3 & -16.7 & -12.9 \\
\hline third quartile & 67,136 & 81,019 & 73,175 & 58,990 & 65,062 & 62,294 & -12.1 & -19.7 & -14.9 \\
\hline Gini & 0.331 & 0.351 & 0.321 & 0.312 & 0.330 & 0.301 & -0.019 & -0.021 & -0.020 \\
\hline \multicolumn{10}{|l|}{ Food consumption } \\
\hline Avg. consumption & 35,216 & 40,269 & 35,452 & 33,983 & 35,698 & 33,150 & -3.5 & -11.4 & -6.5 \\
\hline std deviation & 19,664 & 21,676 & 16,779 & 19,542 & 22,178 & 17,126 & & & \\
\hline Avg. $\log$ cons & 10.36 & 10.49 & 10.39 & 10.32 & 10.36 & 10.31 & -3.8 & -12.2 & -7.5 \\
\hline std deviation & 0.46 & 0.45 & 0.41 & 0.46 & 0.47 & 0.44 & & & \\
\hline First quartile & 22,880 & 26,134 & 24,427 & 22,179 & 23,246 & 22,589 & -3.1 & -11.0 & -7.5 \\
\hline median & 30,419 & 35,038 & 31,683 & 29,111 & 30,702 & 29,483 & -4.3 & -12.4 & -6.9 \\
\hline third quartile & 41,646 & 47,869 & 42,143 & 39,885 & 41,508 & 39,157 & -4.2 & -13.3 & -7.1 \\
\hline Gini & 0.266 & 0.263 & 0.236 & 0.268 & 0.271 & 0.247 & 0.002 & 0.008 & 0.011 \\
\hline \multicolumn{10}{|l|}{ Non food consump. } \\
\hline Avg. consumption & 23,700 & 31,819 & 29,319 & 18,065 & 22,228 & 21,269 & -23.8 & -30.1 & -27.5 \\
\hline std deviation & 35,198 & 54,964 & 44,987 & 28,454 & 35,222 & 30,641 & & & \\
\hline Avg. $\log$ cons & 9.68 & 9.91 & 9.90 & 9.42 & 9.58 & 9.60 & -22.5 & -28.4 & -25.9 \\
\hline std deviation & 0.81 & 0.85 & 0.80 & 0.80 & 0.84 & 0.78 & & & \\
\hline First quartile & 9,089 & 11,214 & 11,449 & 7,316 & 8,201 & 8,600 & -19.5 & -26.9 & -24.9 \\
\hline median & 14,574 & 18,185 & 18,014 & 11,467 & 13,254 & 13,438 & -21.3 & -27.1 & -25.4 \\
\hline third quartile & 25,654 & 33,286 & 31,384 & 19,297 & 23,356 & 23,376 & -24.8 & -29.8 & -25.5 \\
\hline Gini & 0.486 & 0.517 & 0.482 & 0.474 & 0.502 & 0.469 & -0.012 & -0.015 & -0.013 \\
\hline
\end{tabular}

/a For log consumption these columns report $100 *[\exp (\overline{\ln (\text { Core })}-\overline{\ln (\text { Module })})-1]$, for the Gini coefficient the absolute difference. 
Table 2 Differences in average monthly per capita consumption by expenditure group (Rupiah per month, deflated to urban national prices, percentages)

\begin{tabular}{|c|c|c|c|c|c|c|c|}
\hline Per capita monthly & Recall period & Module & std. Error & Core & std. Error & $\begin{array}{l}\text { percent } \\
\text { difference }\end{array}$ & $\begin{array}{l}\text { Contribution } \\
\text { to total /a }\end{array}$ \\
\hline & $\begin{array}{l}1 \text { week for food } \\
\text { and } 1 \text { month for } \\
\text { non-food }\end{array}$ & 75,722 & 1,057 & 61,279 & 648 & -19.1 & 100.0 \\
\hline $\begin{array}{l}\text { Total consumption } \\
\text { (based on yearly non } \\
\text { food) }\end{array}$ & $\begin{array}{l}1 \text { week for food } \\
\text { and } 1 \text { year for } \\
\text { non-food }\end{array}$ & 72,088 & 863 & 57,926 & 623 & -19.6 & 100.0 \\
\hline Food & one week & 40,269 & 256 & 35,698 & 246 & -11.4 & 32.3 \\
\hline Non Food & One month & 35,453 & 889 & 25,580 & 477 & -27.8 & 68.4 \\
\hline Non Food & On year & 31,819 & 666 & 22,228 & 438 & -30.1 & 67.7 \\
\hline Cereals & one week & 9,442 & 39 & 9,107 & 57 & -3.5 & 2.4 \\
\hline Tuber & one week & 497 & 11 & 652 & 11 & 31.2 & -1.1 \\
\hline Fish & one week & 3,468 & 43 & 3,165 & 40 & -8.7 & 2.1 \\
\hline Meat & one week & 2,315 & 44 & 1,972 & 46 & -14.8 & 2.4 \\
\hline Egg and Milk & one week & 2,121 & 29 & 1,937 & 29 & -8.7 & 1.3 \\
\hline Vegetables & one week & 3,623 & 30 & 2,546 & 29 & -29.7 & 7.6 \\
\hline Pulses & one week & 1,420 & 15 & 1,498 & 15 & 5.5 & -0.6 \\
\hline Fruit & one week & 2,075 & 31 & 1,495 & 31 & -27.9 & 4.1 \\
\hline Oil and Fat & one week & 1,765 & 12 & 1,709 & 16 & -3.2 & 0.4 \\
\hline Beverage flavor & one week & 2,196 & 16 & 2,102 & 18 & -4.3 & 0.7 \\
\hline Spice & one week & 1,028 & 9 & 1,175 & 11 & 14.3 & -1.0 \\
\hline Miscellaneous food & one week & 920 & 15 & 830 & 14 & -9.7 & 0.6 \\
\hline prepared food & one week & 6,106 & 93 & 3,895 & 119 & -36.2 & 15.6 \\
\hline alcoholic beverages & one week & 57 & 4 & 104 & 11 & 83.3 & -0.3 \\
\hline tobacco and betel & one week & 3,236 & 29 & 3,510 & 42 & 8.5 & -1.9 \\
\hline \multirow{2}{*}{$\begin{array}{l}\text { Housing, fuel, light and } \\
\text { Water }\end{array}$} & One month & 14,219 & 381 & 9,843 & 241 & -30.8 & 30.9 \\
\hline & One year & 13,803 & 360 & 10,062 & 229 & -27.1 & 25.9 \\
\hline \multirow{2}{*}{$\begin{array}{l}\text { Miscellaneous goods } \\
\text { And services }\end{array}$} & One month & 5,224 & 156 & 2,448 & 72 & -53.1 & 19.6 \\
\hline & One year & 4,722 & 142 & 2,142 & 66 & -54.6 & 17.9 \\
\hline \multirow[t]{2}{*}{ Education costs } & One month & 1,930 & 56 & 2,470 & 127 & 28.0 & -3.8 \\
\hline & One year & 2,089 & 56 & 2,434 & 144 & 16.5 & -2.4 \\
\hline \multirow[t]{2}{*}{ Health costs } & One month & 2,463 & 95 & 2,520 & 122 & 2.3 & -0.4 \\
\hline & One year & 1,227 & 38 & 1,126 & 34 & -8.2 & 0.7 \\
\hline \multirow{2}{*}{$\begin{array}{l}\text { Clothing foodwear } \\
\text { Headgear }\end{array}$} & One month & 4,034 & 89 & 3,134 & 71 & -22.3 & 6.4 \\
\hline & One year & 3,812 & 49 & 2,499 & 37 & -34.5 & 9.1 \\
\hline \multirow[t]{2}{*}{ durable goods } & One month & 5,350 & 511 & 2,909 & 143 & -45.6 & 17.2 \\
\hline & One year & 3,718 & 124 & 2,027 & 85 & -45.5 & 11.7 \\
\hline \multirow[t]{2}{*}{ taxes and insurance } & One month & 834 & 28 & 790 & 43 & -5.3 & 0.3 \\
\hline & One year & 1,033 & 50 & 781 & 27 & -24.4 & 1.7 \\
\hline festivities and & One month & 1,398 & 135 & 1,465 & 85 & 4.8 & -0.5 \\
\hline Ceremonies & One year & 1,415 & 46 & 1,156 & 41 & -18.3 & 1.8 \\
\hline
\end{tabular}

Source: 1996 Susenas data tapes

/a Shares of total for food consumption based on total consumption based on yearly non-food 
Table 3 Differences in average monthly per capita consumption by expenditure group using predicted housing consumption (Rupiah per month, deflated to urban national prices, percentages)

\begin{tabular}{|l|l|r|r|r|r|r|r|}
\hline Per capita monthly & \multicolumn{1}{|l|}{$\begin{array}{l}\text { std. } \\
\text { Recall period }\end{array}$} & Module & Error & Core & std. Error & $\begin{array}{l}\text { percent } \\
\text { difference }\end{array}$ & $\begin{array}{l}\text { Contribution } \\
\text { to total /a }\end{array}$ \\
\hline & $\begin{array}{l}\text { 1 week for food } \\
\text { and 1 month for } \\
\text { non-food }\end{array}$ & 72,671 & 907 & 62,633 & 671 & -13.8 & \\
\cline { 1 - 7 } & $\begin{array}{l}1 \text { week for food } \\
\text { and 1 year for } \\
\text { non-food }\end{array}$ & 69,393 & 693 & 58,998 & 586 & -15.0 & 100 \\
\hline Total consumption & One week & 40,269 & 256 & 35,698 & 246 & -11.4 & 44.0 \\
\hline Food & One month & 32,402 & 741 & 26,934 & 446 & -16.9 & 54.5 \\
\hline Non Food & On year & 29,124 & 486 & 23,300 & 409 & -20.0 & 56.0 \\
\hline Non Food & One month & 11,168 & 172 & 11,197 & 202 & 0.3 & -0.3 \\
\hline Housing, fuel, light and & One year & 11,341 & 173 & 11,368 & 205 & 0.2 & -0.3 \\
\hline Water
\end{tabular}

Source: 1996 Susenas data tapes

/a Shares of total for food consumption based on total consumption based on yearly non-food 
Table 4 Hedonic housing regression estimates

\begin{tabular}{|c|c|c|c|c|}
\hline \multirow[t]{2}{*}{ ep var: $\log$ housing consumption } & \multicolumn{2}{|l|}{ Monthly } & \multicolumn{2}{|c|}{ yearly } \\
\hline & Coefficient & $\mathrm{T}$ value & Coefficient & $\mathrm{T}$ value \\
\hline loor area (in m2) & 0.003 & 65.405 & 0.003 & 66.462 \\
\hline loor area squared & -0.012 & -12.256 & -0.013 & -12.497 \\
\hline \multicolumn{5}{|l|}{ aterial of outer wall (Brick excluded) } \\
\hline wood wall & -0.117 & -17.496 & -0.120 & -17.990 \\
\hline Bamboo wall & -0.074 & -7.625 & -0.087 & -8.959 \\
\hline \multicolumn{5}{|l|}{ aterial of roof (concrete excl) } \\
\hline Wood & -0.202 & -8.201 & -0.197 & -8.026 \\
\hline corrugated zinc/asbestos & -0.225 & -10.268 & -0.214 & -9.772 \\
\hline Tile & -0.237 & -10.827 & -0.216 & -9.886 \\
\hline sugar palm/fibber & -0.454 & -10.845 & -0.429 & -10.262 \\
\hline Leaves & -0.361 & -15.623 & -0.362 & -15.693 \\
\hline Other & -0.391 & -9.749 & -0.385 & -9.616 \\
\hline \multicolumn{5}{|l|}{ aterial of floor (marble ceramic excl) } \\
\hline floor tile & -0.356 & -33.058 & -0.350 & -32.574 \\
\hline concrete/brick & -0.563 & -52.307 & -0.556 & -51.690 \\
\hline wood & -0.640 & -48.122 & -0.619 & -46.573 \\
\hline Bamboo wall (excluded is brick) & -0.611 & -33.873 & -0.595 & -33.038 \\
\hline earth & -0.623 & -49.155 & -0.620 & -48.943 \\
\hline other & -0.500 & -15.710 & -0.495 & -15.589 \\
\hline \multicolumn{5}{|l|}{ ource of light (electricity excl) } \\
\hline privately generated electricity & -0.020 & -1.651 & -0.037 & -3.111 \\
\hline pump lantern & -0.156 & -15.884 & -0.157 & -16.052 \\
\hline kerosene & -0.239 & -35.303 & -0.247 & -36.586 \\
\hline Other & -0.435 & -17.734 & -0.468 & -19.111 \\
\hline \multicolumn{5}{|l|}{ rinking water facility (private excl) } \\
\hline Shared & -0.131 & -21.520 & -0.128 & -21.082 \\
\hline public & -0.136 & -19.204 & -0.136 & -19.238 \\
\hline vendor & -0.108 & -11.334 & -0.109 & -11.415 \\
\hline oes not buy drinking water & -0.052 & -5.865 & -0.051 & -5.728 \\
\hline \multicolumn{5}{|l|}{ ource of drinking water (pipe excl) } \\
\hline pump & -0.076 & -7.225 & -0.079 & -7.569 \\
\hline protected well & -0.223 & -23.106 & -0.221 & -22.980 \\
\hline unprotected well & -0.230 & -21.981 & -0.232 & -22.182 \\
\hline protected spring & -0.257 & -21.098 & -0.252 & -20.712 \\
\hline unprotected spring & -0.218 & -16.489 & -0.218 & -16.522 \\
\hline River & -0.197 & -13.386 & -0.195 & -13.235 \\
\hline rain water & -0.266 & -16.650 & -0.258 & -16.153 \\
\hline Other & -0.059 & -1.999 & -0.080 & -2.735 \\
\hline \multicolumn{5}{|l|}{ ewerage facility (private excl) } \\
\hline Shared & -0.136 & -18.405 & -0.137 & -18.498 \\
\hline Public & -0.133 & -13.830 & -0.136 & -14.169 \\
\hline None & -0.143 & -14.524 & -0.140 & -14.274 \\
\hline \multicolumn{5}{|l|}{ ype of sewerage facility (sitting excl) } \\
\hline Latrine & -0.095 & -11.318 & -0.099 & -11.811 \\
\hline Pit / Hole in ground & -0.132 & -14.350 & -0.135 & -14.689 \\
\hline Does not use & -0.125 & -10.940 & -0.128 & -11.274 \\
\hline \multicolumn{5}{|l|}{ oilet disposal (tank excl) } \\
\hline Pond/ rice paddy & -0.063 & -4.821 & -0.065 & -4.992 \\
\hline River/ lake/ sea & -0.049 & -4.830 & -0.047 & -4.650 \\
\hline Hole in ground & -0.121 & -14.490 & -0.113 & -13.583 \\
\hline Beach / open field / garden & -0.011 & -0.781 & -0.008 & -0.569 \\
\hline Other & -0.054 & -4.609 & -0.055 & -4.707 \\
\hline squared & 0.639 & & 0.641 & \\
\hline
\end{tabular}

Note: provincial crossed with urban/rural dummies suppressed. Complete table available on request. 
Table 5 Poverty estimates with Core and Module data (percentages)

\begin{tabular}{|c|c|c|c|c|}
\hline & & 1993 & 1996 & 1999 \\
\hline \multirow[t]{2}{*}{ Module } & poverty line & 38,246 & 38,246 & 38,246 \\
\hline & head count ratio & 35.0 & 22.4 & 25.2 \\
\hline \multirow{2}{*}{$\begin{array}{l}\text { Core } \\
\text { Poverty line adjusted } \\
\text { using structural } \\
\text { relationship }\end{array}$} & poverty line & 36,981 & 35,207 & 34,671 \\
\hline & Head count ratio & 39.4 & 28.9 & 28.0 \\
\hline \multirow{2}{*}{$\begin{array}{l}\text { Core } \\
\text { Poverty line adjusted } \\
\text { so that the head count } \\
\text { ratios are the same }\end{array}$} & poverty line & 35,187 & 32,378 & 33,454 \\
\hline & Head count ratio & 35.0 & 22.4 & 25.2 \\
\hline
\end{tabular}

Table 6 Estimate of elasticity of per capita consumption using long and short consumption measure

\begin{tabular}{|r|r|r|r|r|}
\hline & \multicolumn{1}{|l|}{ Module } & & \multicolumn{1}{l|}{ Core } & \\
\hline & \multicolumn{1}{l|}{ coeff } & std error & Coeff & std error \\
\hline $\begin{array}{r}\text { primary school } \\
\text { enrollment }\end{array}$ & 0.390 & 0.0140 & 0.446 & 0.0172 \\
\hline junior secondary & 0.543 & 0.0200 & 0.667 & 0.0238 \\
\hline contact rate & 0.0149 & 0.0023 & 0.0245 & 0.0037 \\
\hline Full set of shots & 0.255 & 0.0172 & 0.275 & 0.0206 \\
\hline
\end{tabular}

Note: Housing variables collected in Core used as instruments 
Figures:

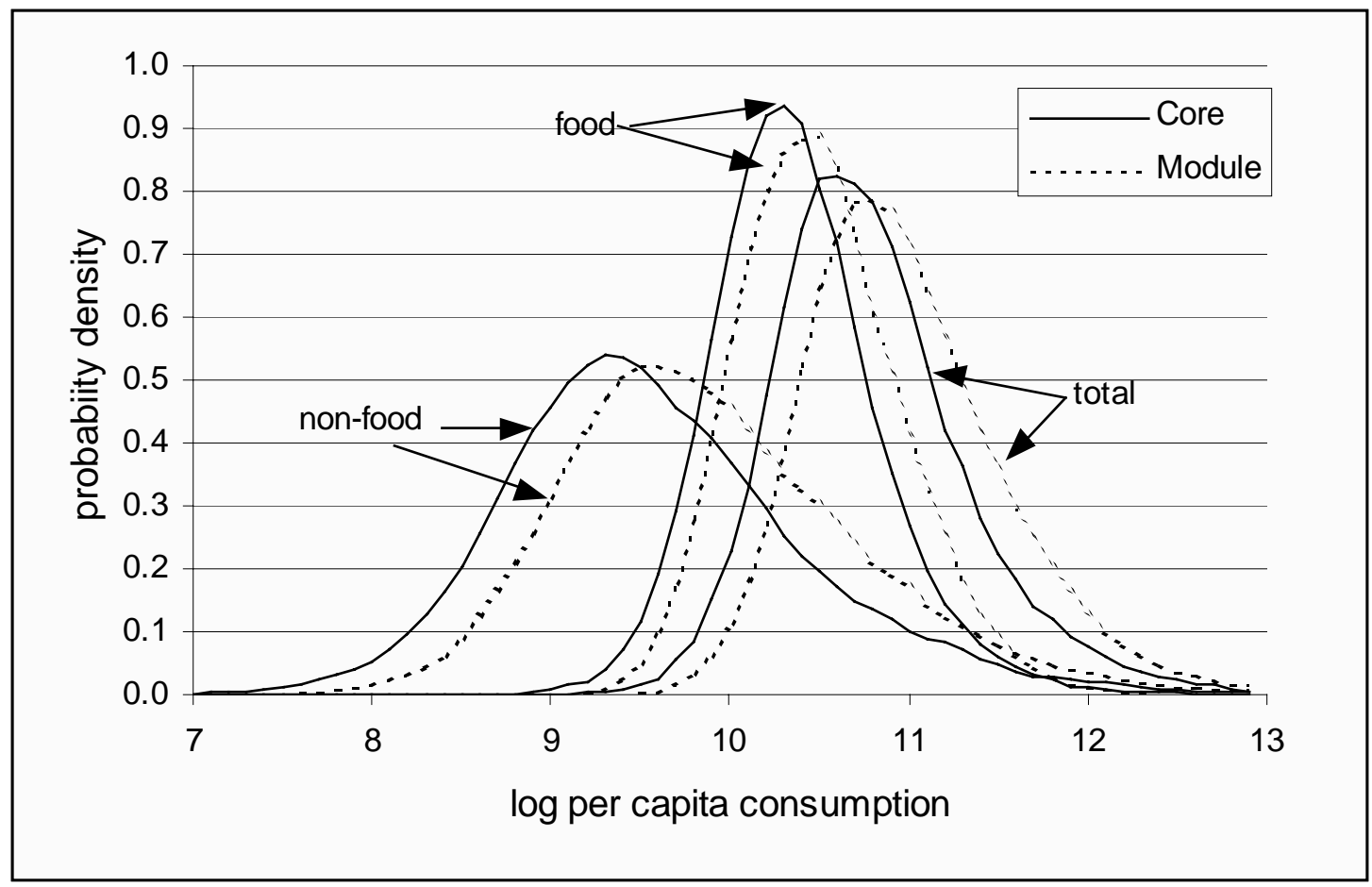

Figure 1 Kernel density estimates for per capita monthly consumption in 1996 


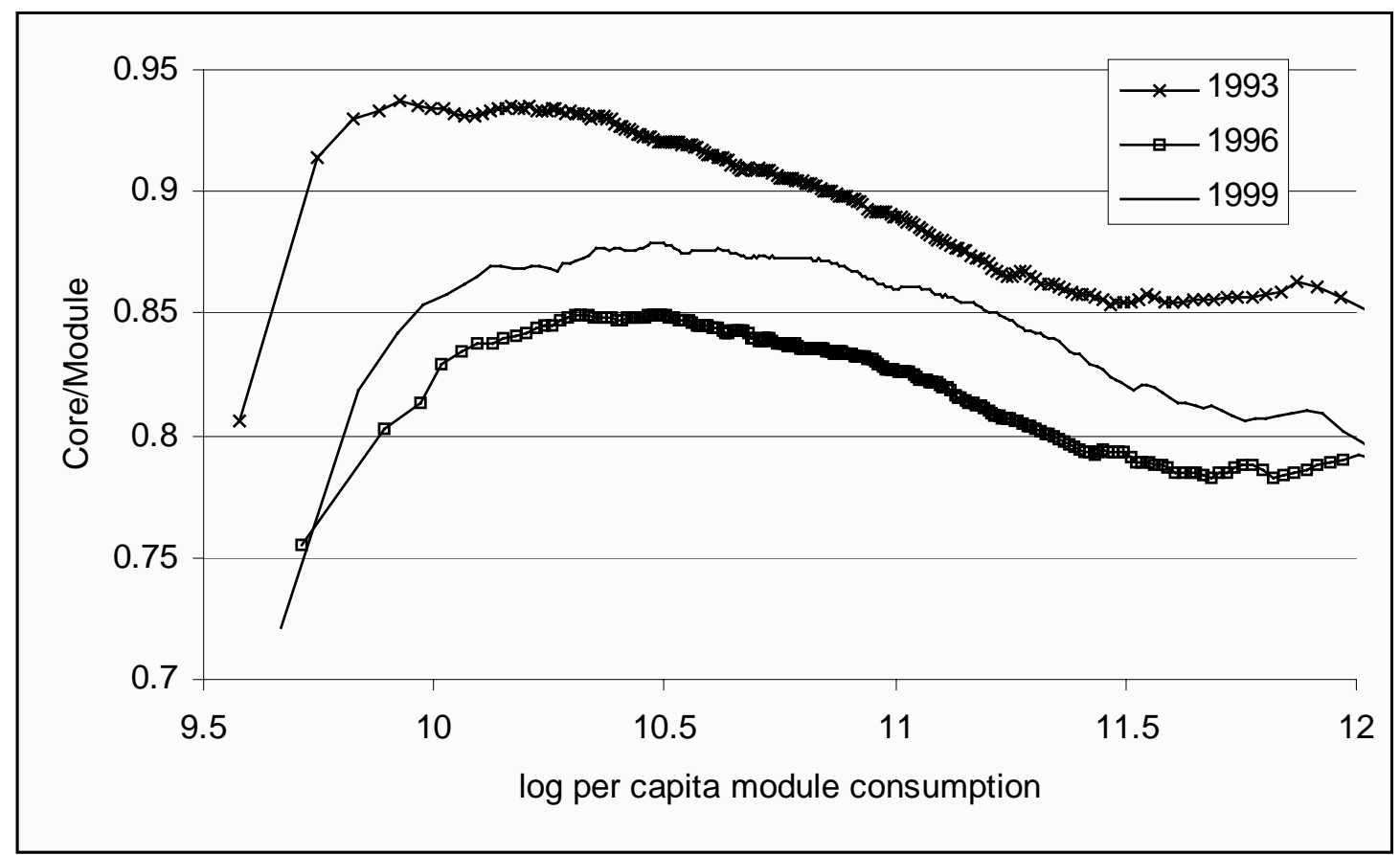

Figure 2 Mapping of distribution functions of per capita consumption of Core and Module (1996 national urban prices)

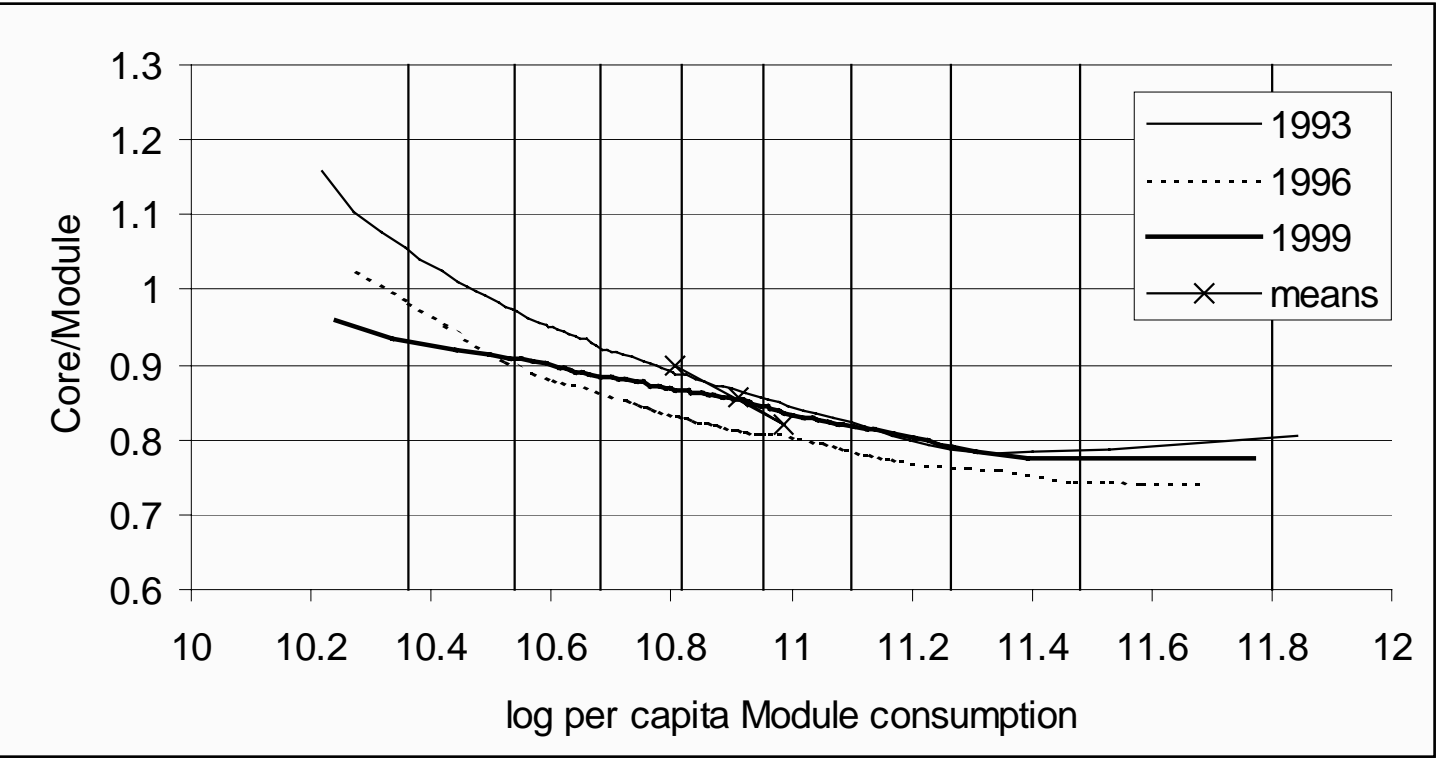

Figure 3 Systematic underestimation of Core consumption (vertical lines denote thresholds for 1996 Module consumption deciles) 


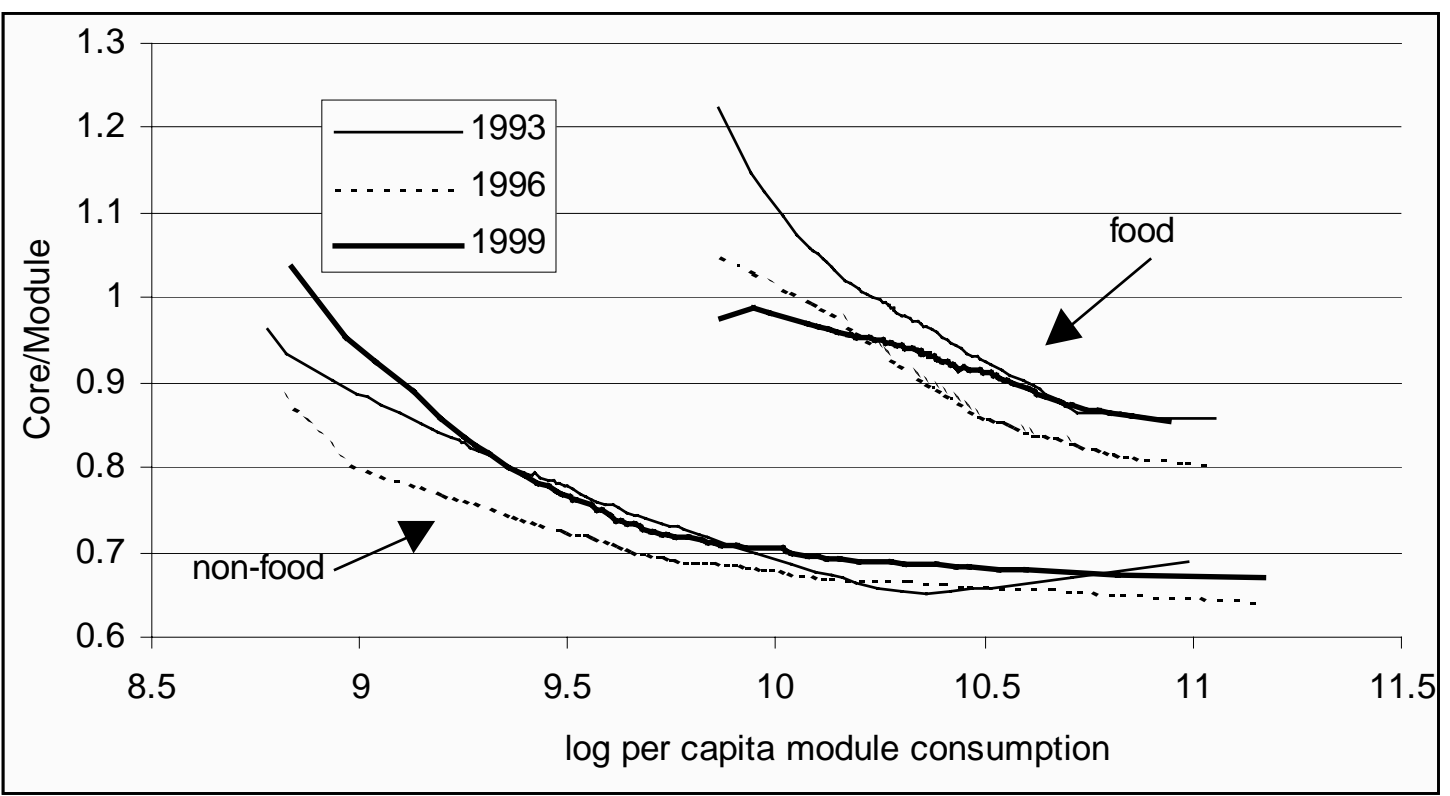

Figure 4 Systematic underestimation of Core food and non-food consumption

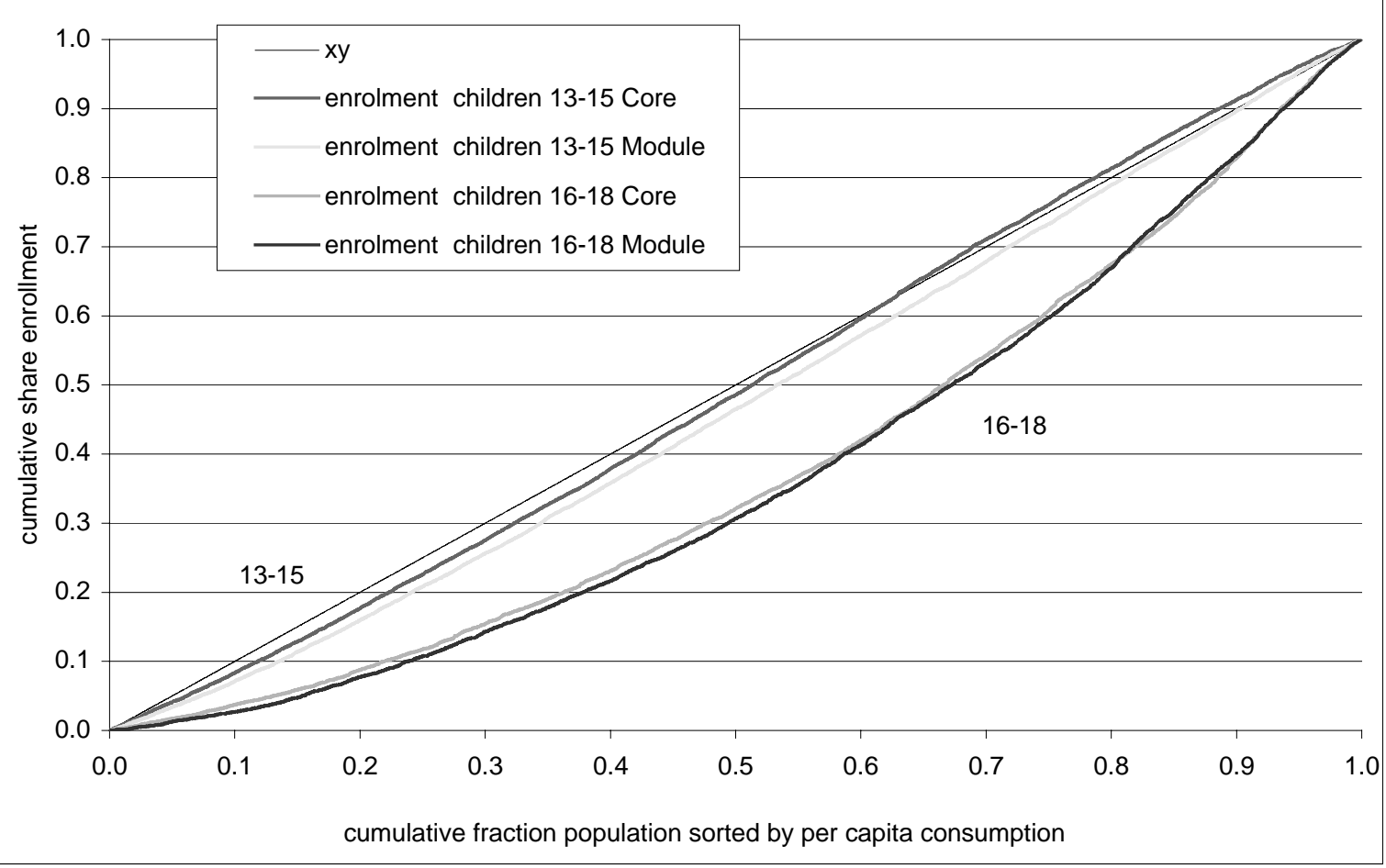

Figure 5 Concentration curves for education using Core and Module consumption 


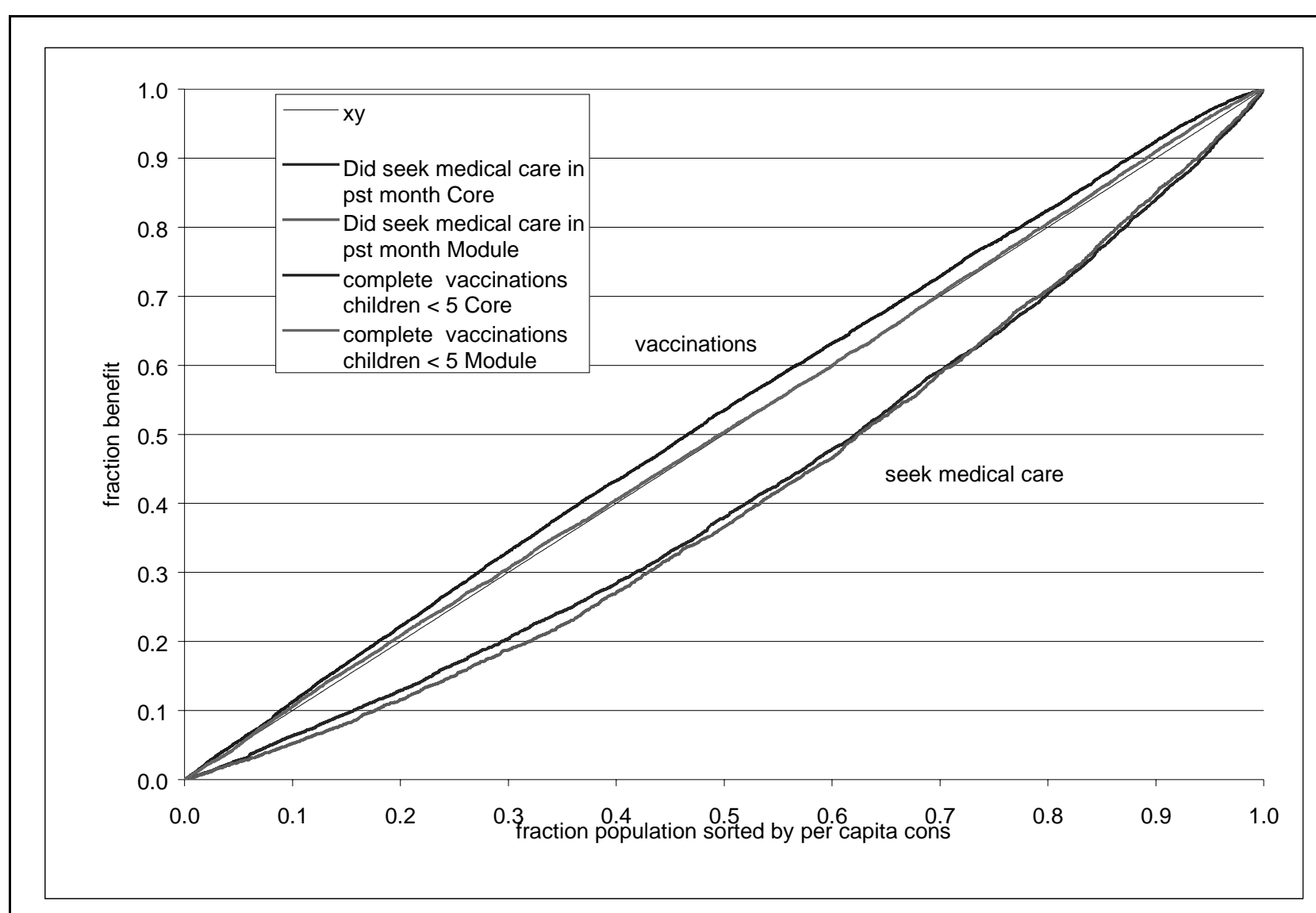

Figure 6 Concentration curves in health using Core and Module consumption 


\section{Left overs}

Figure 1 in totcn.xls

Figure2 in figen.xls

Figure 3 in figfood+nfood.xls

The signal to noise ratio in this case is know because we have the variance of the estimate of the first stage (Deaton, 1985). An estimate of the variance of the measurement error can be obtained by subtracting the variance of the predicted $\ln (s)$ from the variance of the actual $\ln (s)$. Now rewrite (4) as

$\ln (l)^{*}=\frac{\ln (s)-\alpha}{\beta}=\ln (l)+\frac{\varepsilon}{\beta}$

$\ln (l)^{*}$ can be constructed using the estimates of $\alpha$ and $\beta$ and is a noisy estimate of the true $\ln (l)$. Using $\ln (l)^{*}$ as a regressor in (2) reduces the problem to a standard errors in variables model. The signal to signal-plus-noise ratio in this case is $\frac{\operatorname{var}\left(\ln (l)^{*}\right)-(1 / \beta)^{2} \sigma_{\varepsilon}^{2}}{\operatorname{var}\left(\ln (l)^{*}\right)}$.

Summary Montgomery: Very few demographic surveys in developing countries have gathered information on household incomes or consumption expenditures. Researchers interested in living standards therefore have had little alternative but to rely on simple proxy indicators. The properties of these proxies have not been analyzed systematically. We ask what hypotheses can be tested using proxies, and compare these indicators with consumption expenditures per adult, our preferred measure of living standards. We find that the proxies employed in much demographic research are very weak predictors of consumption per adult. Nevertheless, hypothesis tests based on proxies are likely to be powerful enough to warrant consideration. 


\begin{tabular}{|r|r|r|r|}
\hline & inflated module figure & National account figure & $\begin{array}{r}\text { Factor of } \\
\text { underest }\end{array}$ \\
\hline 1993 & $95,256,000,000,000$ & $192,958,000,000,000$ & 2.025678 \\
\hline 1996 & $164,160,000,000,000$ & $331,586,000,000,000$ & 2.019895 \\
\hline 1999 & $326,900,000,000,000$ & $730,317,000,000,000$ & 2.234069 \\
\hline
\end{tabular}

Commentaar Rob

In the conclusion, discuss what you can do with the scaling which follows from the structural underestimation. You can calculate averages under the assumptions of measurement error as I proposed them. You cannot calculate poverty indices by simply setting a core poverty line at the level so that the head counts are the same. You could discuss this in the theoretical part also and maybe derive a correction factor (which probably depends on the mean level of consumption) under the normality assumptions.

$>$ In the descriptive parts, add a table with higher moments. Std deviations (of the log) and quantiles. Also add a graph with the kernal density estimates of the pdfs. In table 2 it does not make much sense to report the standard errors, std deviations make more sense since they will not get smaller as the sample size increases.

You could refer to the following paper if you can get it on the underestimation of the FES: Author: Banks, James, and others Source: How reliable is the family expenditure survey? Trends in incomes and expenditures over time; Publication: London: Institute for Fiscal Studies, 1998 Doc.

Note that the weights add up to the population. Pweights are used.

In the pseudo cross section. Derive to a specification which acknowledges that you use simple means. Not with a averaged error term. This seems wrong 
You could add an analysis on whether there is are any structural effects on the underestimation. Are certain groups more prone to underestimate than others. Work this estimation out nicely. You first estimate $l=X \beta+\varepsilon$ on the module. Then you estimate $s=\alpha \hat{l}+Z \gamma+\eta$ The gammas would give you an estimate of how the systematic underestimation varies by type of person. You have to define some exclusion restrictions on $\mathrm{Z}$ since otherwise the system is not identified. These could be proxies for local labor market conditions (they influence your earnings, but not your ability to answer questions). You could also consider taking a functional specification of the variance $\sigma^{2}=\exp (X \delta)$ so that you can, given this structure, see whether certain groups underestimate more, or make more measurement error, than others. Look at

Permanent Income, Current Income, and Consumption: Evidence from Two Panel Data Sets Journal of Business and Economic Statistics v14, n1 (January 1996): $81-90$

If you estimate the model above without $\mathrm{Z}$, this boils down to the same as the structural relation estimate that I performed earlier in the paper. If $X$ only contains regional dummies, this is exactly the same. If you add more variables to $X$ you increase the number of data points for your second stage regression. But the measurement error on the lhat increases. You should do some sensitivity analysis. Also look at the article of Kloek somewhere way back in Econometrica that discusses regression in case all the regressors are constant within a group. Don't underestimate the standard errors.

$>$ The problems seems that. $\mathrm{Y}=\mathrm{xb}+\mathrm{e}$ from module. $\mathrm{S}$-predicted $\mathrm{y}=\mathrm{xb}$ from core. What does

it get you?

Hedonic housing regression. Acknowledge Jensen inequality $\exp (\mathrm{E}(\ln y))=$ not $\mathrm{E}(\mathrm{y})$. Under normality it is $\exp (\ln (\mathrm{h}) \mathrm{pred}) * \exp ($ sigma squared/2). Recalculate predicted housing consumption this way and test for normality of the error terms.

Check formula for updating, add in table 5 non adjusted poverty line on Coredata 